\title{
NUCLEAR AND RELATED TECHNIQUES FOR ENHANCING LIVESTOCK AND AGRICULTURE PRODUCTIVITY
}

\author{
D. R. Khanal (PhD) ${ }^{1}$ and R. C. Munankarmy $(\mathrm{MSC})^{2}$
}

\begin{abstract}
Uses of isotopes and nuclear related techniques in livestock and agriculture are discussed in this review. How developed countries are using $\left({ }^{125} \mathrm{I}\right)$ in radioimmunoassay (RIA) of progesterone hormone in serum/milk of cattle to optimize reproductive efficiency is briefly described. In addition, this paper discusses about the uses of $\left({ }^{15} \mathrm{~N}\right)$ in soil to know the dynamics of nitrogen and uses of Hydro Probe to determine moisture content in the soil. This review will also shed some light on the potential uses of isotopes and nuclear techniques and the necessity of such technology in Nepal for improving overall agricultural productivity.
\end{abstract}

Key words: Radioimmunoassay, progesterone, productivity, reproductive efficiency

\section{INTRODUCTION}

Developed countries have been enjoying the benefits of nuclear and related technologies for enhancing animal productivity and health since last 2-3 decades whereas countries like Nepal is yet to realize their importance for augmenting ever increasing demand of agricultural and livestock products to feed exploding population growth. As of February 2009, 146 countries have become the Member States of International Atomic Energy Agency (IAEA), the United Nations' regulatory body for the peaceful uses of atomic energy in the world (IAEA, 2009). The neighboring countries, India and Pakistan which are also members South Asian Association for Regional Cooperation (SAARC) became the Member States of IAEA five decades ago during 1957 while another neighbor, Bangladesh received the membership in 1972 that has similar economy like ours. Sri Lanka and Afghanistan also became member states of IAEA long time ago. Most of our neighbors have been exploiting nuclear technologies for peaceful uses in the diverse fields such as agriculture, animal production and health, disease diagnosis and cancer therapy. Nepal is unable to exploit the multiple usages of nuclear technologies except in the medical field for diagnostic imaging with $x$-rays and cancer therapy. The vast agrarian Nepalese economy has yet to exploit nuclear technologies and enjoy their fruition.

Remarkable improvements in livestock productivity in the developed countries have achieved through research into how animals grow and how yields can be influenced and protected, followed by the widespread uptake of new techniques and materials. Many of the advances in improving the feeding, fertility and health of livestock have been possible with use of nuclear techniques. Biological processes responsible for growth, reproduction and disease resistance in different farm animals are manipulated for greater productivity through the use of radioisotopes (Dargie, 1990).

1 Animal Health Research Division, PO Box 3733, Kathmandu, Nepal

2 Soil Science Division, Khumaltar 
The impact of isotopic methods in the development of feeding strategies for farm animals has been very heavy. Animal nutritionists establish the nutritional value of all the materials potentially available to feed animals through tracer techniques by tagging feed constituents, amino acids and other metabolites with isotopes such as ${ }^{14} \mathrm{C},{ }^{125} \mathrm{I},{ }^{51} \mathrm{Cr}$, and ${ }^{15} \mathrm{~N}$. With tracer technique, the fate of the feed constituents, amino acids and metabolites can be followed within the digestive system and other parts of the body. Isotopic methods have developed the modern nutritional concepts and the adoption of these concepts has increased the rates of growth and yields of milk and meat besides improving the quality (Dargie, 1990). The following table gives an insight about the production trend of livestock products in developed and developing countries.

Table1.Comparative performance of cows in developing and developed countries (Dargie, 1990)

\begin{tabular}{lll}
\hline & Developing countries & Developed countries \\
\hline Milk yield/cow & 300 litres & 5000 litres \\
Calf crop & In every 2-3 years & Annually \\
\hline
\end{tabular}

\section{USES OF RADIOIMMUNOASSAY (RIA) FOR IMPROVING ANIMAL REPRODUCTION}

Before 1960, bioassays were used for hormonal assays but since last three decades, RIA kits have been used to assay small ligands like tyrosine, progesterone and cortisol. Highly sensitive RIA using ${ }^{125} \mathrm{I}$ or ${ }^{3} \mathrm{H}$ has been developed and used to measure the minute quantities of reproductive and other hormones circulating in the blood that control reproduction. RIA of progesterone $\left(\mathrm{P}_{4}\right)$ has been essential to the development of the present day highly efficient breeding practices that go in hand with better feeding to increase productivity. RIA has made it possible to determine when animals are ready for breeding, diagnose pregnancy earlier than would be otherwise possible, check whether animals have been inseminated at the correct time, devise corrective measures for reproductive disorders and improve the efficiency of artificial insemination and embryo transfer programs (Dargie, 1990).

Although widely used in many laboratories in developed countries, RIA technology has not been transferred to many countries in the third world. Still many countries of the developing world have not gained membership of IAEA and Nepal being a new member has to fulfill financial obligation before making her eligible for getting technical projects in the diverse areas of agricultural and medical sciences. Moreover, the short life of RIA kit reagents is one of the major problems besides the problems associated with the cost and the regular supply of kits overseas. Handling of radiochemical and the subsequent disposal of radioactive waste is another problem. Although single channel readers are relatively inexpensive, the time taken to read large numbers of samples precludes their use for large-scale epidemiological surveys. The larger automated gamma counters are prohibitively expensive and difficult to maintain under local conditions. The health hazard of inexperienced staff handling radiochemical must also not be overlooked (FAO/IAEA, 1993).

In recent years, livestock productivity has been increased by improved reproduction. Excepting few leading farmers in Nepal, majority of the farmers are waiting till full term pregnancy (9-10 months period) after mating on the pretext of being pregnant without opting for pregnancy diagnosis. But when the animal fails to calve at the end of full term pregnancy, farmers are losing a lot and despite of that they seem least concerned and unaware of economic losses incurred for rearing the unproductive animal. By adopting a simple technique of assaying blood/milk progesterone $\left(\mathrm{P}_{4}\right)$ at 24 days after mating, one could find out whether 
the animal is non-pregnant or not. Once the farmer knows that his/her animal non pregnant, he/she can go for immediate re-mating in the subsequent cycle (Dargie, 1990) days oestrus cycle) without wasting time and money. In this way, reproductive efficiency can be optimized. Besides, $\mathrm{P}_{4}$ assay will help to monitor the state of pregnancy as its low level in already pregnant level may warrant exogenous administration in case of threatened abortion. Likewise, repeat breeders can also be monitored with $\mathrm{P}_{4}$ assay (FAO/IAEA, 1993)..

\section{USE OF NUCLEAR TECHNIQUES (DNA PROBES) IN ANIMAL HEALTH:}

Conventional approaches of disease diagnosis involving isolation and direct detection of microorganism by microscopy and immunoassay usually take long time while nucleic acid hybridization techniques are very promising in terms of time and sensitivity. This hybridization technique is unique as it focuses on the genome of the organism and not its products, viz., the proteins. Most common label used in DNA probe technology is a radioactive one $\left({ }^{32} \mathrm{P},{ }^{35} \mathrm{P},{ }^{125} \mathrm{I}\right)$ incorporated directly into the nucleic acid by one of the several techniques available. After hybridization, the duplex (probe-target) is detected by liquid scintillation counting or by auto-radiography. This technology is very sensitive. However, major drawbacks are short half-life of the radioisotopes (14 days for $\left.{ }^{32} \mathrm{P}\right)$, requiring frequent preparation of new probes, and requirement for special equipment for handling and storage of radioactive products and health risks inherent in the use of isotopes (Dargie, 1990). Recently, Technetium $99 \mathrm{~m}$ is routinely used for diagnosing hyperthyroidism in dog and cats, cases of chronic lameness in horses and portosystemic shunt in liver. The most common indication for bones scan is lameness that cannot be localized by physical examination, survey radiographs or ultrasound scan. "Hot spots" are areas of increased bone remodeling activity produced by neoplasia, infection or trauma ( Lavin, 1999).

Nuclear techniques have played the vital role in the field of animal health. Ionizing irradiation from ${ }^{60} \mathrm{Co}$ or X-ray sources have been used to eliminate the virulence of some parasites to produce safer and cost effective vaccines. In UK alone, the commercial use of an irradiated vaccine against lungworm disease in calves saves livestock producers over US $\$ 10$ million each year (Dargie, 1990). Radioactive lodine $\left({ }^{131} \mathrm{I}\right)$ is most valuable for treating small functional nodules of metastatic disease that are hard to find or treat surgically. Radiation therapy in dog and cat is given mainly for the treatment of primary brain tumors (total dose $45 \mathrm{~Gy}$ in 3.75 Gy fractions over 28 days) (Lavin, 1999).

Nuclear and related techniques make an important contribution to efforts to improve livestock productivity and food security through better management of feed resources, reproduction and control of diseases (FAO/IAEA, 2008).

\section{USES OF RADIOISOTOPES IN METABOLIC STUDIES:}

Radioactive amino acids can be used for metabolic labeling of tissue culture cells. Most commonly used radioactive precursors for labeling protein is $\left({ }^{35} \mathrm{~S}\right)$ Methionine because its decay is easier to detect and it is easily incorporated into protein and its incorporation is linear over a wide range of added label. Other amino acid labels used are: $\left({ }^{3} \mathrm{H}\right)$ Proline, $\left({ }^{35} \mathrm{~S}\right)$ Cysteine and $\left({ }^{3} \mathrm{H}\right)$ Leucine (IVRI, 2001). 


\section{MISCELLANEOUS USES OF RADIOISOTOPES:}

Commercial manufactures sterilize surgical sutures, syringes, cotton wool, gauzes and different biomaterials used in patients by ${ }^{60} \mathrm{Co}$ (IAEA, 2009). Besides, for characterization of chemical ingredients ${ }^{1} \mathrm{H}$-NMR and Solid State ${ }^{13} \mathrm{C}$-NMR are often used.

\section{USES OF RADIOISOTOPES FOR FOOD SAFETY:}

In many countries, health and safety authorities have approved irradiation of more than 40 different foods, e.g., spices, grains, chickens, fruits and vegetables based on the standard adopted by the Codex Alimentarius Commission, a joint body of FAO/WHO. The irradiation is ideally suitable for foods of animal origin, especially those to be consumed raw or minimally processed (FAO/IAEA, 2008). Irradiated food commodity presents no toxicological hazards and requires no further testing since it introduced no special nutritional or microbiological problems in foods. The presence of potentially harmful substances in meat and other food products can also be monitored using RIA to safeguard their quality.

\section{OTHER USES OF RADIOISOTOPES IN AGRICULTURE:}

In developed countries, nuclear related technologies are being used routinely for studying soil fertility, plant breeding, plant mutation, crop production, insect and pest control, animal production and disease diagnosis. Multifaceted uses of radioisotopes in agricultural sciences include (FAO/IAEA, 2008):

a) Soil science: To optimize the use of soil resources (nutrients and water), to increase crop productivity and to optimize the impact on the environment of the excessive use of fertilizers. ${ }^{15} \mathrm{~N}$ is used to quantify the amount of biologically fixed nitrogen in field grown legumes and also to know the dynamics of ${ }^{15} \mathrm{~N}$ applied to soil for crop production. An accurate measurement of soil moisture content using nuclear (soil moisture neutron probe) is essential for establishing the optimal soil-water balance for irrigation scheduling under different irrigation systems and soil management practices.

b) Plant breeding: Radiation can be used to induce mutations and generate genetic variation from which desired mutants with improved agronomic traits are selected. In addition, seed can be irradiated using nuclear techniques. This contributes to the intensification of food production and the achievement of food security.

c) Entomology: The sterile insect technique (SIT) is based on the mass rearing and release of male insects, which has been sexually sterilized (infertile) by radiation. At mating, they cannot fertilize the females and no progeny is produced. This technique eventually leads to the control or eradication of insect pests of major crops and insect vectors of diseases with a substantial reduction in the use of insecticides. In Africa, SIT has been found promising in the control of the fruit fly causing damage to more than 200 varieties of fruits and vegetables, and the tsetse fly, the vector of trypanosomiasis.

d) Agrochemicals: Farm to fork approach to food safety is promoted through analytical methodologies for detecting contaminants such as mycotoxins, pesticides and veterinary drugs in food and environmental samples.

\section{CONCLUSIONS:}

Although Nepal is far behind the developed countries in terms of food security, she has to start from the scratch with no further delay in exploiting the nuclear and related technologies 
to enhance food and animal productivity for meeting the ever increasing demand of food security.

\section{REFERENCES:}

Dargie, J. D., 1990. Helping small farmers to improve their livestock. International Atomic Energy Agency, Vienna.

FAO/IAEA, 1993. Progesterone RIA Kit Protocol. Joint FAO/IAEA programme in animal production and health.

FAO/IAEA, 2008. Nuclear technology serving agriculture. The Joint FAO/IAEA Programme of Nuclear Techniques in Food and Agriculture in http://www-naweb.iaea.org/nafa/index.html (Dec, 2008)

IAEA, 2009. History of the IAEA. International Atomic Energy Agency available at http://www.iaea.org/About/Policy/MemberStates/index.html (April, 2009).

IVRI, 2001. Practical manual of analytical biochemistry. Division of Biochemistry and food science, Indian Veterinary Research Institute, India.

Lavin, L. M., 1999. Radiography in veterinary technology. W. B. Saunders Company, Philadelphia. 